\title{
La ciudad informal latinoamericana. Desde Uruguay a Colombia
}

\section{Vivian Andrea Ladino Mosquera ${ }^{1}$}

\section{viladito30@gmail.com}

Álvarez-Rivadulla, M. J. (2017). Invasiones y políticas de la marginalidad en Uruguay. New York, EE.UU.: Palgrave Macmillan

En su libro "Invasiones y políticas de la Marginalidad en Uruguay", del año 2017 y publicado en la Serie de Economía Política de América Latina de Palgrave Macmillan, María José Álvarez-Rivalluda parte de unas preguntas generales sobre ¿Cómo se forma la ciudad informal? ¿Cómo las personas van construyendo su vida en esos contextos? ¿Cómo se crean las redes clientelares con el Estado a manera de sobrevivencia?, además de abordar temáticas como la sociología de la desigualdad, la pobreza y la política.

Se destaca que el abordaje de la investigación se hace, entre otras, desde el marco teórico de la política contenciosa de las movilizaciones sociales propuesto por Tilly y Tarrow, quienes plantean que son las oportunidades políticas y no solo las necesidades sociales las que llevan a que un grupo de personas decida tomarse un pedazo de tierra por la fuerza, es decir que se actúa basado en los signos de apertura de lo que es viable para que el sujeto se movilice en determinado momento de la historia.

1 Trabajadora Social. Especialista en Procesos de Intervención Social. Estudiante de la Maestría es Estudios Sociales y Políticos. 
Eso no quiere decir que las necesidades no sean tenidas en cuenta como factores de movilización y ocupación de tierras, sino que sonvarios los factores causales de la invasión, lo cual implica reflexionar sobre los medios políticos para actuar. Esto es un punto de referencia valioso para ver la ocupación de tierras en Cali y sobre todo en el Jarillón, pues la gente no se establece únicamente por su falta de vivienda y empleo, sino que la permisividad de los gobiernos de turno y la no vigilancia del Estado son oportunidades políticas precisas en ese momento.

En consecuencia, los autores analizan sus problemas de estudio a partir deseries detiempo,yesesoloquese propone metodológicamente Álvarez-Rivalluda al indagar el crecimiento de las invasiones en un periodo largo de tiempo. Y es que lo importante de mirar los ciclos de ocupaciones no es el hecho físico de radicarse en la zona, sino por qué se da en un momento específico de la historia y no en otro, es prestarle atención al tiempo.

Sin embargo, la autora no se queda en la revisión de prensa y el seguimiento a noticias que son el insumo para reconstruir el fenómeno sistemáticamente, sino que rápidamente se da cuenta que las huellas de las invasiones se pueden apreciar mejor al hablar con los habitantes de los lugares, por eso termina realizando un proyecto multimétodo en el que mezcla la revisión de prensa-archivo con trabajo de campo etnográfico de 1 año (entre 2006 y 2007).

Para el trabajo con fuentes primarias se propuso recorrer los barrios locales, hablar con el primer residente, y obtener no solo una versión, sino varias a partir de entrevistas retrospectivas, que a pesar de haber sido difíciles y mostrar lo imperfecto de los datos, logran dar una mirada más amplia del fenómeno. Esta estrategia metodológica da cuenta de la importancia de tomar diversas técnicas de recolección de información para indagar procesos de ocupación en el tiempo, pues hay datos que ofrece el periódico y el archivo histórico que no ofrecen los habitantes, y viceversa. 
En este orden, la autora empezó con la revisión de bases de datos geográficos y les puso fechas para ir construyendo la línea de tiempo. Logra ver que en todo el interior de la ciudad se regaron cerca de 400 invasiones, y desde el aire se ven como barrios formales, pues tienen calles definidas, pero se diferencia de los asentamientos por goteo donde no hay espacios entre las viviendas, sino que están apiñadas, lo cual sí brinda un punto de comparación con los asentamientos del Jarillón.

Figura 1-2: Mapas de los asentamientos ilegales en Montevideo y Cali $^{2}$

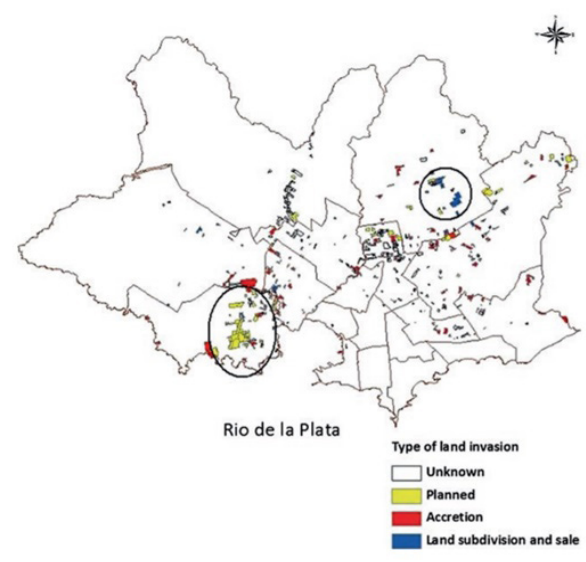

Fuente: Álvarez-Rivalluda (2017:76)

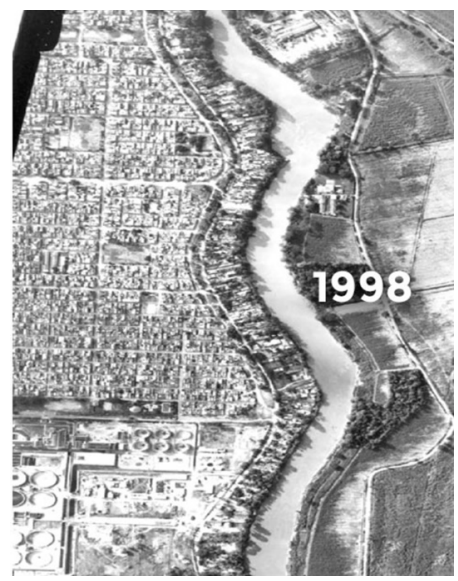

Fuente: El pais de Cali 2016

2 El primer mapa muestra las 3 principales formas en que ha sido poblada Montevideo (planificada, acreción, subdivisión y venta), señalando que la panificada se ha hecho sobre tierras estatales, mientras que las que se han subdividido para la venta, fue en terrenos privados que se convierten en posibilidad de negocio. Resalta en la imagen que esta última forma (color azul) es la de mayor porcentaje, y se ubica en su mayoría en la periferia de la ciudad. Lo anterior permite contrastar los asentamientos informales en Cali, donde si bien se encuentran en su mayoría en la periferia, las tierras ocupadas en su mayoría son estatales, que según ÁlvarezRivalluda (2017), facilita la ocupación por la poca atención que el Estado brinda a la vigilancia de estas tierras, es decir, un factor común entre Montevideo y Cali. 
Para Álvarez-Rivalluda una de las ideas centrales que se puede establecer a partir de las imágenes, es que las invasiones en Montevideo son una especie de "industria de la invasión", pues en su mayoría fueron planificadas, dado que un grupo determinó qué hacer; creó normas; estableció quién entraba y quién no; incluso no permitía que las viviendas se quedaran informales, sino que debían mejorar los materiales después de dos meses o de lo contrario se iban.

Lo anterior también evidencia que en medio de las invasiones se transferían ideologías sindicales y solidaridad laboral, lo cual tenía que ver con el tipo de líderes de las zonas planificadas, pues cita el ejemplo del barrio "El Cerro" donde los ocupantes eran anarquistas hijos de obreros. Situación que tiene que ver con la influencia que tuvieron los denominados grupos de izquierda e incluso de insurgencia en el establecimiento de relaciones sociales interclase, además de la consolidación y mejoramiento barrial en el Distrito de Aguablanca (Rodríguez, 2013).

De otra parte, la autora problematiza otra idea y es que las invasiones se caracterizan por ser focos de pobreza creados a partir de tomas de tierra a la fuerza o por goteo (Ilegada de uno en uno) en contextos de crisis económica, al encontrar que en Montevideo el pico de apropiación se da en medio de 3 características distintas que sustentan su tesis: ocurrió 10 años después del proceso de democratización; el país se encontraba en una época de bonanza económica; y se contó con el apoyo del Estado a manera de clientelismo de sobrevivencia.

El fenómeno en Montevideo crea entonces una ruptura con relación a la tendencia latinoamericana donde los procesos de migración del campo a la ciudad se dieron entre la década del 50 al 80 debido la crisis de la deuda externa, el Consenso de Washington, las guerras civiles, y la represión en el continente, favoreciendo el crecimiento en los centros urbanos a partir de asentamientos informales (Vargas y Jiménez, 2013). 
En ese contexto el incremento poblacional fue tan alto, que "el promedio de Argentina, Brasil, Chile, Colombia, México, Perú, Ecuador y Venezuela creció de un 47\% a un 70\% entre 1950 y 1980" (Vargas y Jiménez, 2013, p. 3), mientras que iniciada la década del 80, la ciudad uruguaya no contaba con un número alto de invasiones, siendo que hacía ya 10 años se había dado el proceso de democratización con la eliminación de la dictadura, y la economía del país iba por buen camino.

En consecuencia, es posible contrastar el caso atípico de Montevideo con el poblamiento del Jarillón de Cali que es un reflejo de la tendencia latinoamericana, pues la urbanización se caracterizó por el descontrol y la poca ligazón con políticas públicas municipales, en la que el comportamiento demográfico de Cali fue una transición de lo rural a lo urbano que estuvo acompañada de propaganda clientelista, promesas de viviendas e inclusión de nuevas tierras habitables (ejidos), compra de votos, problemas de inundación, entre otros, que determinaron el proceso de ocupación de la ciudad y sus alrededores (Uribe, 2009).

Aunque la capital del Valle tendría dos caras para relacionarse con el proceso de la ciudad uruguaya, en tanto el Distrito de Aguablanca y la Ladera llegan a consolidarse en barrios reconocidos legalmente gracias a incipientes procesos de planificación y redes políticas construidas con partidos políticos. Pero no todos los asentamientos llegan a consolidarse en barrios, sino que el dique de protección que atraviesa la ciudad es hasta la fecha el soporte de 12 asentamientos de desarrollo humano incompleto en zona de alto riesgo no mitigable que impiden la legalización de la zona, y por ende agregan otra variable que no aparece en Montevideo.

Esa otra cara de la moneda podría relacionarse con los procesos de goteo que también se dieron en la ciudad uruguaya, pero en menor medida. Estos lugares que debido a la forma apiñada en que se consolidaron, a la no regularización de la población que llegaba ni al mejoramiento barrial de lavivienda, además deser población recicladora 
y con economía agrícola, se diferencian de los barrios planificados con influencia política, y se asemejan más a la realidad del Jarillón de la ciudad, pues la forma en que se rellenó el dique y se construyeron las viviendas, además de las actividades de subsistencia económica de los habitantes y el no mejoramiento de los materiales de las viviendas en los últimos 30 años, son claramente puntos de comparación.

Vale la pena destacar que la serie de tiempo que tanto le apasionaba construir a la autora, es la base para analizar el contexto de ese proceso, pues ella encuentra varios picos que relaciona con la apertura democrática, la cual se relaciona por un lado con el primer partido de izquierda que llega al poder, justamente porque se genera más competencia por los votos de los pobres en estas zonas que son indispensables para ganar las elecciones. Situación similar a la del Jarillón, pues no ha habido consejo y alcaldía de la ciudad que no haya llegado al poder sin prometer a las familias del dique que no van a ser desalojados de la zona y que pronto serán legalizados.

Por otra parte, la autora señala que la democratización baja la represión del gobierno y ya no te matan por participar, lo cual aumenta la competencia electoral y promueve la descentralización del acceso a las instituciones. De modo que se dan 2 etapas de movilización: una de tipo reactiva que ocurre antes que termine la dictadura y se da a cargo de "los más pobres de los pobres" ante la amenaza de desalojos.

En este punto la iglesia tuvo mucho que ver porque los curas que vivían en los barrios fueron los que también transfirieron capacidades organizativas a la población en un contexto de dictadura que fue paralelo al nacimiento de la teología de la liberación. Ejemplo similar al del crecimiento de los barrios del distrito de Aguablanca y la Ladera, pues el surgimiento de las organizaciones comunitarias de base estuvo relacionado con las iniciativas religiosas y de caridad -extranjeras- que realizaron las primeras inversiones sociales en las zonas (Rodríguez y Bermúdez 2013). 
Un segundo momento de la movilización estuvo relacionado con la influencia del voto y el clientelismo, donde ya no es la iglesia sino los partidos políticos los que ayudan a consolidar las oportunidades políticas en las invasiones y los hacen a partir de 3 mecanismos: uno es el esfuerzo deliberado por parte de la izquierda para ganar; el segundo es que cuando gana la izquierda hay una aliado influyente que está dispuesto a negociar; y el tercero es que hay una especie transacción con la entrega de tierras, es decir que el gobierno se vuelve un aliado de estas ocupaciones, tanto así que presenta como un logro del Estado que el 11\% de la población invadiera.

Finalmente señala que el pico de bajada de la toma de tierras tiene que ver con los mismos picos de subida como lo señala Tarrow, retomado por Álvarez-Rivalluda, y es que ya no hay, sino que empiezan a faltar las oportunidades políticas, por ende, también decrece la competencia electoral y los recursos económicos, pues ya no se está en tiempos de bonanza y por el contrario arranca la crisis económica del 20022004. No obstante, aunque desaparecen las condiciones de invasión señaladas al principio, la toma de tierras no se elimina por completo en Montevideo.

La autora concluye gracias al análisis de la serie de tiempo, que es en los años electorales y con crisis económica donde aumenta la probabilidad de ocupación de tierras. Conclusión aplicable al Jarillón, donde las casi 25 mil personas que habitan la zona son el botín electoral que siguen compitiendo los partidos políticos tras las campañas electorales cada 4 años. El resultado: un dique fracturado, sin mantenimiento y en riesgo de inundar la ciudad.

Si bien cada año que la autora visita alguno de los barrios legalizados en Montevideo, tienen un ladrillo o un piso nuevo, en el Jarillón de Cali cada vez que se visita la zona se encuentra una nueva vivienda, pero no con material renovado y con miras a la formalización, sino con paredes de cartón y techos de plástico, las cuales difícilmente va a sujetarse a procesos de mejoramiento barrial debido a la incertidumbre del 
desalojo, pero sobre todo a las nefastas políticas neoliberales que como en los inicios de la década del 80, siguen siendo un factor de crisis económica y estancamiento social para Latinoamérica.

\section{Bibliografía}

Álvarez-Rivalluda, M. J. (2017). Squatters and the politics of marginality in Uruguay. Bogotá: Latin American Political Economy.

Rodríguez, R. (2013). Coyunturas políticas interclase. Élites, profesionales y comunidades en la conformación del Distrito de Aguablanca (Cali, Colombia, 1980 - 1995). (Tesis doctorado). Universidad Javeriana, Bogotá, C.

Rodríguez, A. N. y Bermúdez, C. (2013). Intervención social y organizaciones comunitarias/populares en Cali. Cali: Ediciones Universidad del Valle.

Uribe H. (2009). Acción colectiva y toma de tierra en los jarillones de los ríos Cali y Cauca en Santiago de Cali-Colombia. En: Rodríguez M. y Roze J. (Ed.), Ciudades Latinoamericanas IV: Políticas, acciones, memoria y reconfiguración del espacio urbano (69-90). México: Universidad Autónoma de Guerrero, Consejo de Ciencia y Tecnología y Asociación Latinoamericana de Sociología.

Vargas, I.etal. (2010). Procesos de mejoramiento barrial participativo en asentamientos informales: propuesta de integración en la ciudad de Ibagué (Colombia). Revista Invi, 68, 59-96. Recuperado de: http://www. redalyc.org/articulo.oa?id=25816623002

y Jiménez,E.(2013).Integraciónsocio-espacialdeasentamientos informales en Ibagué, Colombia. Un proyecto de cooperación al desarrollo. Revista Bitácora Urbano Territorial, 23, 117-128. Recuperado de: http:// www.redalyc.org/pdf/748/74830874015.pdf 